\title{
Idiopathic aqueductal stenosis
}

\section{Emma Deavin, Rajiv Madula, Paul Grant and Masud Haq}

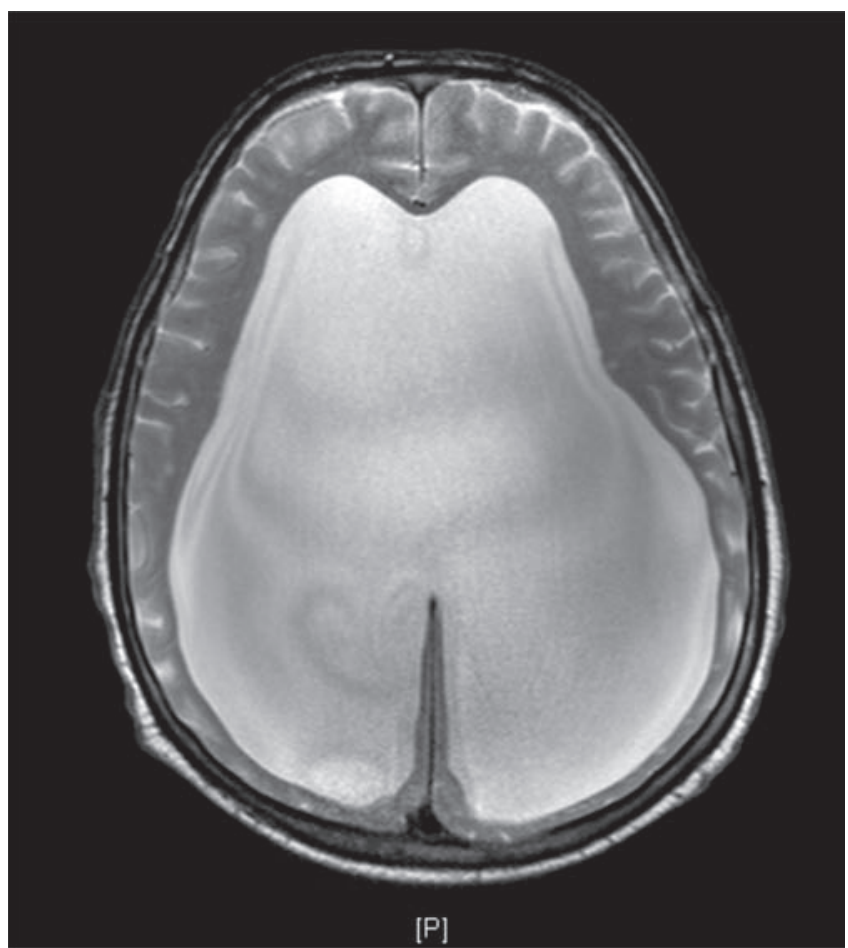

Fig 1.

A 67-year-old-man with learning difficulties presented with worsening confusion, urinary incontinence and impaired mobility. A computed tomography (CT) scan, followed by an magnetic resonance imaging (MRI) scan of the brain demonstrated dramatic appearances, including massive lateral and third ventriculomegaly with gross displacement of the surrounding supra-tentorial brain substance. The point of obstruction appears to be the central aqueduct and this is clearly chronic in nature and was thought to account in part for his previous diagnosis of 'learning difficulties'.

Address for correspondence: Dr Masud Haq, Department of Medicine, Tunbridge Wells Hospital, Pembury, Kent.

Email: masudhaq@nhs.net

Emma Deavin, FY2 trainee; Rajiv Madula, CT2 trainee; Paul Grant, SpR in diabetes and endocrinology; Masud Haq, consultant physician

Tunbridge Wells Hospital, Kent, UK

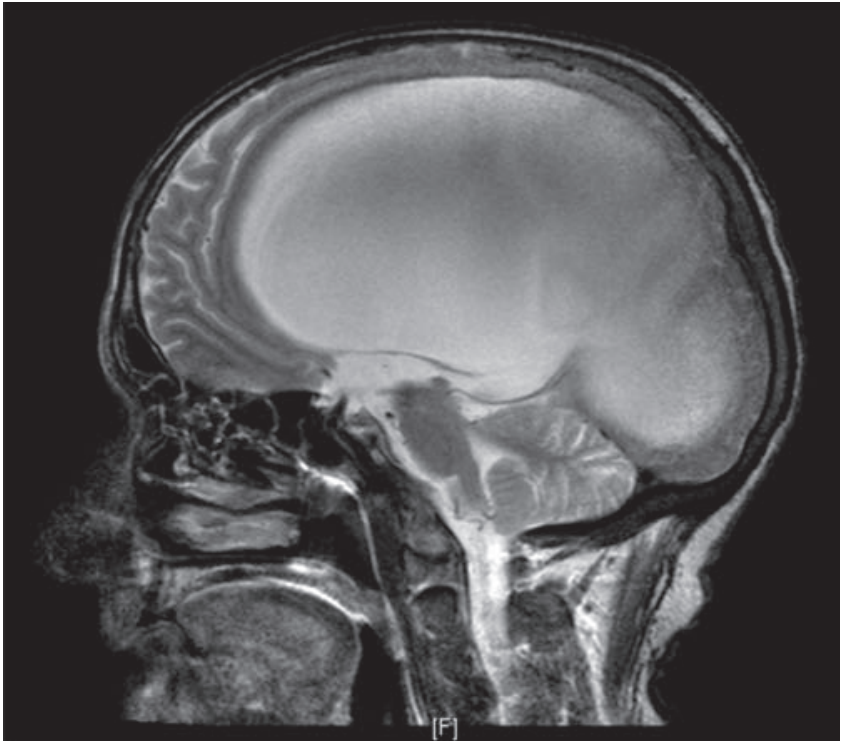

Fig 2. 